\title{
Reaching Communities with the Social Resilience Message: Be Prepared
}

\author{
Jamie Richards \\ Civil Defence and Emergency Management, Auckland Council
}

\begin{abstract}
Building resilience to natural and man-made disasters has become a dominant strategic theme and an operational goal in many countries around the world. Of the many parts making up resilient communities, this paper discusses what is commonly termed Social Resilience, and in particular the "education" of communities to initiate a culture of preparedness for them to be able to maintain essential functions for their families/communities in the event of "disruption" to everyday life, whether it be large or small. By examining case studies in New Zealand and internationally, this study looks at a way forward for Auckland, New Zealand's largest city, to achieve a greater level of preparedness amongst its citizens. It is hoped the paper will provide empirical evidence on how to translate the notion of social resilience into initiatives applied by the local government to help communities be better prepared for future disaster events.
\end{abstract}

\section{INTRODUCTION}

This paper sets out primarily to provide a way forward for Auckland to move our communities to a higher level of preparedness. It is not likely to provide solutions but rather reflect on practices from around the world in an attempt to identify a long-term strategy and inform decisions.

The research method employed for this paper is a literature review on current trends, research, practices, theories, and initiatives in both New Zeland (NZ) and worldwide. These have been investigated and compared, with the best options for Auckland being identified in this paper.

The author has been the senior adviser for public education with Auckland Civil Defence and Emergency Management, a department of Auckland Council in NZ, since November 2010. During this time, multiple initiatives have been developed and implemented, including the adoption of NZ's national campaign "Get Ready Get Thru."

According to Colmar Brunton polls, despite money and hard work the number of "fully prepared" Aucklanders remains one of the lowest in NZ. When compared to other surveys (Auckland Council, 2013), there is some doubt on the validity of the poll, however the author has noted through research and observation that the way "disaster education" is delivered, and in particular our messaging, needs to change to have any real effect on the levels of preparedness in Auckland.

Resilience is the elixir of survival (Ripley, 2008) and as typical in the "disaster" sector, the terms and definitions used vary. For example, community resilience can be defined as the ability to mitigate and withstand the stress of disaster (RAND Corporation, 2013); social resilience is the capacity to foster, engage in, and sustain positive relationships and to endure and recover from life stressors and social isolation (Cacioppo, Reis, Zautra, 2011). Social resilience is the timely capacity of individuals and groups-family, community, country, and enterprise-to be more generative during times of stability and to adapt, reorganize, and grow in response to disruption (Leitch \& Sutton, 2013). According to Paton, Smith, \& Johnston (2005), community resilience "is a measure of how well people and societies can adapt to a changed reality and capitalise on new possibilities offered." Resilience involves the ability of a community to not only resist and recover from a hazard event but also to adapt to the changes that the event may cause. It includes the ability of a community to learn from experiences and to improve its systems and capabilities for the next event. Preparedness plays a pivotal role in disaster resilience.

This paper does not set out to discuss resilience in its broadest sense; rather it looks at the emergency preparedness part of resilience, and how to achieve this. It is important to understand that what is being discussed is one small part of a bigger resilience picture, but to discuss the small part without reference to the larger picture is not possible. This needs to be kept in mind whilst reading this paper. The paper also touches on the theories, practices, and other aspects of public education.

In NZ, we do not have organisations such as the Federal Emergency Management Agency (FEMA) or a large military force we rely on to manage our disasters (Ministry of Civil Defence and Emergency 
Management [MCDEM], n.d.). Put another way, we have limited resources and a capacity to respond to major disasters. Our model is one of coordination and collaboration of government departments, organisations, groups, and businesses that we "organise" to provide services during disasters. A big part of this model is the reliance on our citizens to be prepared for disasters. With an understanding of our model, it will be realised that being successful with our preparedness campaigns are important.

Additionally, since the London bombings, there has been an international move to devolving responsibility and authority for decisions to the level of those closest to the risk and best able to manage it and the emphasis on building local preparedness and encouraging resilience in communities, organisations, networks, and critical infrastructure (Manley, 2013a).

\section{ABOUT AUCKLAND}

The Auckland Council is dedicated to the vision of making Auckland, "the world's most liveable city" (Auckland Council, 2014). An integral part of this vision is to minimise the effects an adverse event would have on the community.

The region administered by the Auckland Council covers 4,900 square kilometres and is the home to more than $1,530,000$ people, a population which is increasing by $1.4 \%$ every year. With imports currently at 14.1 million tonnes a year and with a gross domestic product of $\$ 42.2$ million, Auckland is now a critical component to the future successes of New Zealand. Safe and secure communities provide the stable base on which to build Auckland into an international economic and social power house (Auckland Council, 2014).

Auckland's population is in a state of constant change with more than 185 different ethnicities now living in the city. Ethnic migration, particularly from Asia, now accounts for the single biggest influence on Auckland's demographic profile. Maori and Pacific populations will continue to increase whereas the European population will age and proportionately decrease as a ratio in the general population. The changing profile of Auckland's population in the short to medium term provides increasing and variable challenges to delivering safe and secure communities for all the city's citizens. The task of community safety and development is understand those challenges and how to best meet the changing needs of Auckland's increasingly diverse communities (Auckland Council, 2014).

\section{DISCUSSION}

\subsection{What Is Public Education?}

Public education means different things to different people and organisations. It includes many actors and activities. It can be different campaigns by different organisations or coordinated campaigns across organisations (Mileti, 2008).

Public education was also found to fall into four categories: (1) Public education (where the campaign consisted mostly of providing the public with information via various media), (2) social marketing, (3) community development programmes, and (4) psychological preparedness (Finnis, 2004).

Dufty (2010) defines community education as any learning process or activity that builds community resilience. He uses the term "education" in its broadest sense and includes learning both in formal (e.g., schools) and nonformal (e.g., community events) settings. Community education can include:

- Public communications, information products, and services

- Training, development, and industry-specific programs

- Community development programs

- Comprehensive personal education programs (Dufty, 2010)

The Hyogo Framework for Action 2005-2015: Building the Resilience of Nations and Communities to Disasters highlights knowledge and education as one of the five main priorities of action (Building Research Institute, \& National Graduate Institute for Policy Studies [BRI, GRIPS], 2007).

\subsection{The Logic Behind Our Public Education}

Auckland utilises logic similar to the bush fire example Rhodes (2011) gives in Figure 1 to deliver education but also attempts to address known encumbrances on the journey to preparedness, for example, barriers to action.

We utilise a three-pronged strategy to deliver our messages to our communities; these are defined geographic areas, communities of interest, and open public education. In defined geographic areas, we organise Emergency Response Groups (ERGs) and plan with them for emergencies while also educating them on preparedness. Communities of interest include disabled, faith-based, cultural, and linguistic groups; that is, groups that come together with a common cause but are not geographically linked. Open public education is the "catch" of all the others (Manley 2013b). We ask all groups to "champion" our message, thus increasing the people we are able to reach.

There is a known Social Psychology of Hazard Education (Mileti, 2003). From a theoretical viewpoint, public hazards communication and education works best when the public materials and approaches used bring about uncertainty in the minds of people, causing them to wonder about their environment and to question their safety in it. Good public education gives people something to mull over 
84

and to discuss with friends, family, and colleagues. It sparks interest enough that people generate questions and then seek more information to answer their questions, and its specialists are there with additional and clear information when the questions are asked. Desired changes in the public may take some time to materialize (Mileti, 2003).

\subsection{The Science of Teaching (Pedagogies) Preparedness}

Preparedness campaigns aim not only to alter individual cognitions concerning emergencies but individual behaviours, the ways in which they make decisions of costs and benefits of following actions or not, their emotions, and even their sense of personhood as a citizen. Various pedagogical devices are used in achieving this. These pedagogies can be classed as below:

1. Banking and didactic [message]

2. Construction kit [items]

3. Affective

4. Family and community learning

5. Performance

6. Public

The above list is not exhaustive, and a single classification does not always fit an individual preparedness pedagogy which may be classed along a number of axes. For example, a preparedness campaign might be devised to be both affective and construction kit, engaging emotions through a practical project (Preston, 2012).

\subsection{Is Our Public Education Effective?}

On June 27-28, 2012, FEMA and the American Red Cross (Red Cross) hosted a workshop to discuss how to improve preparedness messaging to encourage the public to prepare themselves and their families for a disaster. After 2 days of intensive discussions, participants including academics and researchers; practitioners; and private sector partners came to an important conclusion-while this is not easy and there is no silver bullet, the potential exists to significantly improve our preparedness messaging strategies FEMA \& American Red Cross, 2013).

\subsection{Factors Preventing Preparedness}

To complicate processes in which we engage our communities, barriers to preparedness (Figure 2) and action exist, including psychological barriers ( Paton, 2006; Finnis, 2004). The manner in which our diverse populations in Auckland perceive risk is another barrier, as is the Lake Wobegon effect (Ripley, 2008; Lake Wobegon, n.d.).

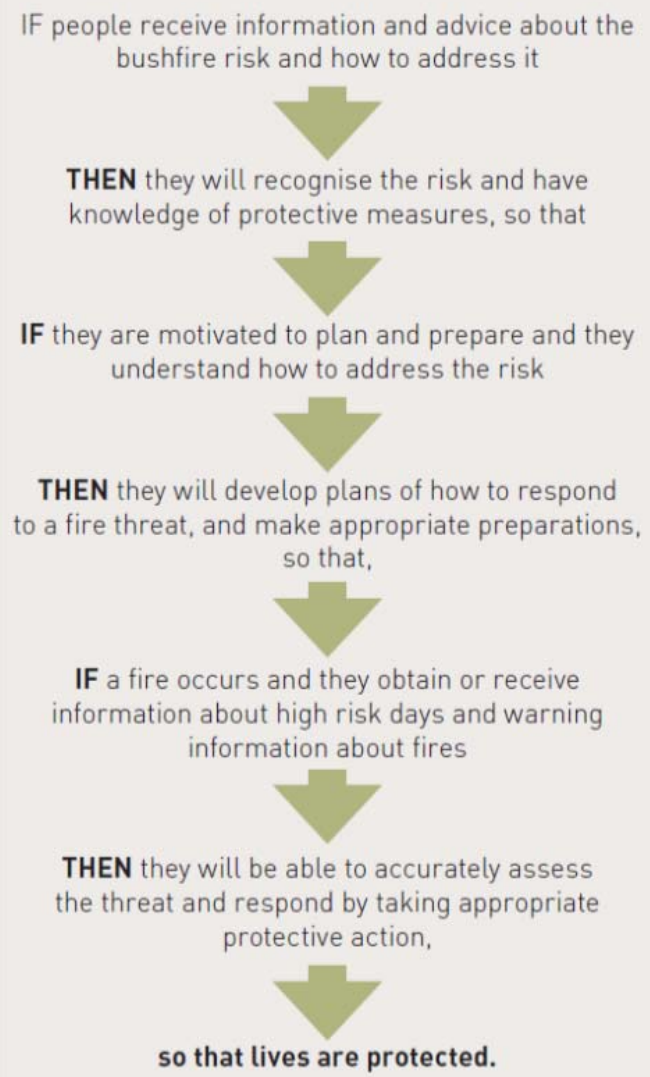

THEN they will recognise the risk and have knowledge of protective measures, so that

IF they are motivated to plan and prepare and they understand how to address the risk

THEN they will develop plans of how to respond to a fire threat, and make appropriate preparations, so that,

IF a fire occurs and they obtain or receive information about high risk days and warning information about fires

THEN they will be able to accurately assess the threat and respond by taking appropriate protective action,

so that lives are protected.

Figure 1. Logic of community education approach (Rhodes, 2011)

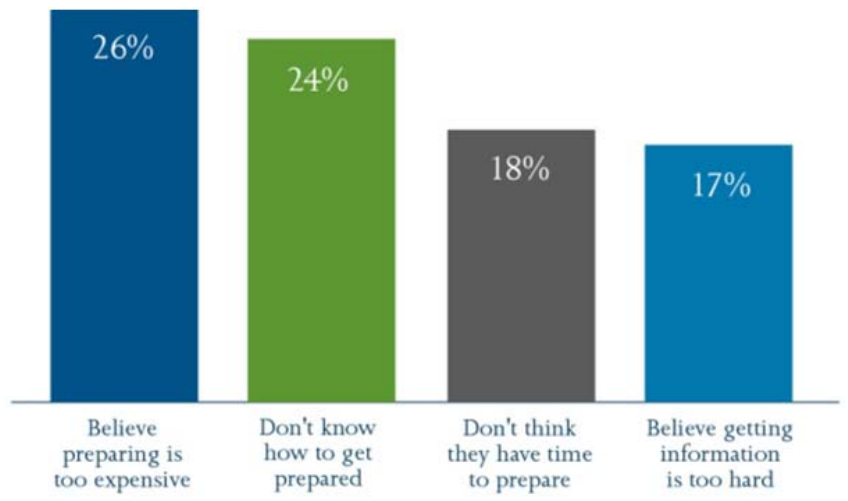

Figure 2. Perceived barriers to preparedness (FEMA, 2013)

\subsection{How Do We Improve Our Preparedness Levels?}

Building a culture and the practice of disaster resilience is neither simple nor inexpensive (Committee on Increasing National Resilience to Hazards and Disasters, Committee on Science, Engineering, and Public Policy, Policy and Global Affairs, \& The National Academies, n.d.). Community resilience is not just the business of civil defence emergency management agencies. Perhaps, if resilience was embraced collectively by all that have an interest in it, it could be delivered holistically and could be measured by factors such as a strong and vibrant community where the norm is residents who participate; minimal crime; clean streets, how well our communities are prepared, and so on. This is the concept of where Auckland Council wants be with 
the concept of "the world's most liveable city" (Auckland Council, 2014).

It is important to provide tangible and everyday things that communities can immediately recognise and thus create momentum which more are likely to embrace and join.

This type of initiative could be achieved by community hubs (an example can be seen at: http://www.tcc117.org/en/ [Takatori Community Centre, n.d.]). This kind of community led and driven approach may be far more effective than current community resilience initiatives.

\subsection{Strategy}

Locally in Auckland and nationally in NZ, public education strategies are in place. These mostly address the points discussed by Dufty (2011) who recommends:

- That engagement and education processes are linked where possible in strategic plans to enable breadth and depth of learning in communities;

- To position their engagement and education strategic plans in relation to the National Strategy for Disaster Resilience;

- To encourage shared responsibility for community learning, for example, through the development of local engagement/education plans involving local residents and businesses;

- To use social media as a disaster resilience learning tool in addition to traditional engagement and education activities;

- To evaluate all engagement and education strategies, programs, and activities.

\subsection{Why Educate}

"I believe for every dollar you spend on preparedness you save $\$ 9$ in response," Honore said. "The biggest example I can get you is: You go down to your grandma's house that has that big old tree next to it that's 200 years old that can fall on grandma's house and kill her. On a given day you can go cut that tree for $\$ 1,000$. You wait until after the tornado hit or after the hurricane hit, and it's going to cost you about $\$ 10,000$ to remove it. That is if grandma is still alive."

\subsection{The Message}

In Auckland, there has been a growing dissatisfaction with the national "Get Ready Get Thru" initiative. This is mirrored in the US. Jones (as cited in McKay, 2012) wraps it up:

If you look at the campaigns that are put out there, they aren't preparedness campaigns, they're branding campaigns. But if you're going to give a big, broad-based, scattergun preparedness message, it should be nonthreatening and something everybody can do. It's such an upper-class, Americanprivileged message to think that people have resources for some time in the next 30 years when there's an earthquake.

The way [the message] is conveyed is problematic. "It's threat-based, top down, put forth by agencies whose mission, mind-set, and muscles are around disaster response, not preparedness," Jones said. "There's a different way to leverage resources in a community than to tell everybody, 'You need to have this, otherwise horrible stuff is going to happen to you.' The proper message isn't tied to having a kit but to developing resilience every day. Community organizations, churches, schools, businesses, and the like are better positioned in the community to deliver a more resonating message. People need to hear the message from people they believe in" (McKay, 2012).

Auckland currently uses the national campaign "Get Ready Get Thru." It has been realised that the public do not receive this message well. It is too top down, it is confusing, it denigrates, and it is out dated. We are already looking to make our messages relevant, simpler, encouraging, and positive. There are good examples of "better" at www.readyscotland.org and www.sf72.org.

\subsection{Clearer Communications}

Have you ever asked yourself what is the purpose of teaching emergency drills, such as Drop Cover Hold? Amanda Ripley raises an interesting concept in her book, "The Unthinkable Who Survives When Disaster Strikes-And Why," with the concept of the survival arc. The survival arc comprises of three stages, each of which you have to process to reach

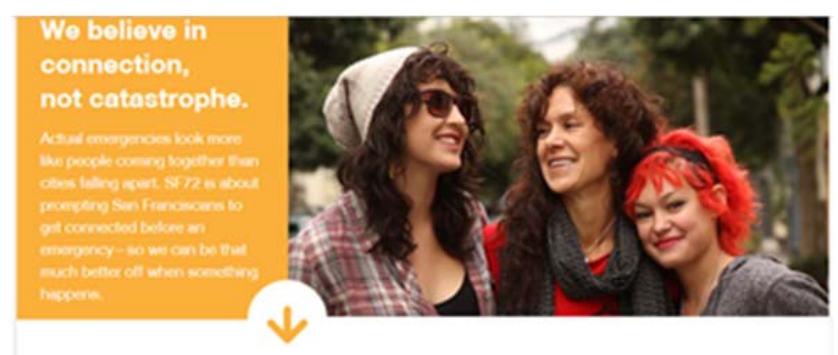

Good news. You're more prepared than you think. Learn more...

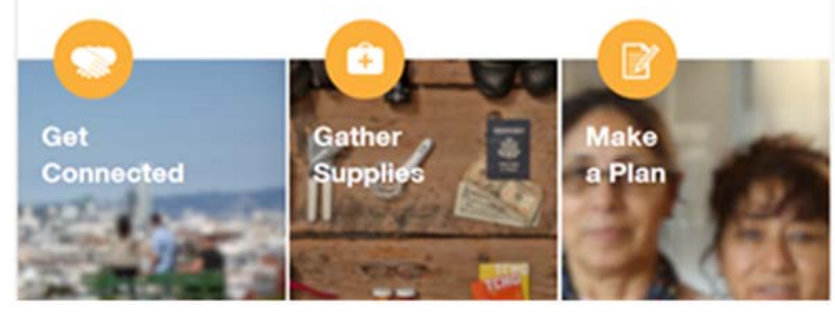

Figure 3. Positive messaging example (San Francisco Department of Emergency Management, n.d.) 
86

the next level. The three stages are (1) Denial (this cannot be happening to me), (2) Deliberation (what should I do), and (3) Action (do it [Ripley, 2008]). What teaching emergency drills does is eliminate? Stages 1 and 2 and take you straight to Stage 3, Action. Without explanations like this, we are blindly asking the public to learn/adopt something without explaining why, other than, "this may save your life one day."

A noteworthy parallel is that the act of preparing helps you prepare psychologically for an emergency. A functional Household Emergency Plan helps alleviate fears about potential disasters, makes actual disaster situations less stressful, and saves precious time in the face of disasters (MCDEM, 2010). This message is not listed as a key message on the Ministry of Civil Defence and Emergency Management web site.

\subsection{How Human Beings Comprehend Risk}

Yet another factor that needs to be built in to public education is how human beings comprehend risk.

People who study decision making agree that human beings do not go around like risk assessors, doing calculations and multiplying probabilities. "That's been disproved," says Paul Slovic (2004), a psychology professor at the University of Oregon and one of the world's most respected experts on risk. Instead, people rely on two different systems: the intuitive and the analytical. The intuitive system is automatic, fast, emotional, and swayed heavily by experiences and images. The analytical system is logical, contemplative, and pragmatic. One system can override the other depending on the situation (Ripley, 2008). Both systems operate in parallel and each seems to depend on the other for guidance. Through understanding how risk is perceived, we can begin to build meaningful messages into public education (Slovic, 2004).

\subsection{Creating a Culture of Preparedness}

Human behaviour is a crucial factor in the degree of vulnerability and the likelihood of disasters taking place. Here, education (knowledge) plays a significant role in society. Since disasters are infrequent in nature and memories are short in terms of passing knowledge from one generation to another, there is a need to promote culture of prevention (BRI \& GRIPS, 2007).

When disaster strikes, [Aucklanders] must be prepared. We need to be ready to care of family members, assist our neighbours, and work effectively in teams and alongside first responders and other emergency workers. We will need adequate stores of water, food, and supplies to support a citywide response. Comprehensive publicdisaster education and neighbourhood-based training and resource coordination are necessary for engaging all residents of the city in an ongoing preparedness effort (RJWestmore, n.d.).

\subsection{Community Engagement Is the Key}

Cacioppo et al. (2011) say the key to resilience is not individual strengths alone. Social resilience depends on the development of greater awareness of our connections with others and multiple capacities for social action that can lead to the attainment of both personal hopes and social purposes. Choices informed by social connection as well as personal values lead to resilient outcomes that are sustainable with respect to the social worlds in which we live as well as personal motivations for success and long life. Programs are required to assure us that people can face calamities better as a group than they could alone.

McKay (2012) promotes that people need messages in different forms, and they need it from trusted sources, like churches, schools, and employers. Oden says, "What you should do is seek out groups and community leaders, be it community centres or churches. People are much more connected today to groups of like interests than ever before, and if we as emergency managers are focusing on the leaders of those groups, then they can pass the preparedness message down to citizens" (McKay, 2012)

\subsection{Creating a sense of community ownership}

The Wellington Region Emergency Management Office (WREMO) has developed a community resilience model, applicable to any emergency management agency, to enhance connectedness and preparedness. This community-driven approach relies on evidence-based community development methodologies to enable better engagement, stronger partnerships, and empowered communities who rely less on government-led intervention (Joint Centre for Disaster Research, 2013)

FEMA began its national dialogue with a proposition: a community-centric approach for emergency management that focuses on strengthening and leveraging on what works well in communities on a daily basis and offers a more effective path to building societal security and resilience (FEMA, 2011).

\subsection{Equip the Community}

Two Community Emergency Response Teams already exist in Auckland. Developing more of these teams would not only give communities a sense of ownership, belonging, and a satisfaction of community participation, but it would also provide a focal point and portray the message "this can happen-we are preparing you for this"-all of which could be considered part of education. It would also provide trained and prepared residents who could effectively assist first responders after a disaster without running unnecessary risk to themselves and 
others. The Neighborhood Emergency Response Team (NERT) program trains San Franciscans to do just this (Aldrich et al., 2008).

In her book, "The Unthinkable Who Survives When Disaster Strikes-And Why," Ripley (2008) promotes programs such as NERT. She says:

In most disasters, the vast majority of rescues were done by ordinary folks. After the first 2 hours, very few people came out of the debris alive. We have snapped plates of armour on to our professional lifesavers. In return we have very high expectations for these brave men and women. Only after things go wrong, do we [communities] realise we are on our own. No fire department can be everywhere no matter how good their gear.

\subsection{Tell the Public, Be Honest, Give Them Reasons to Prepare}

We need our communities to know who we are. We need to be visible. We need to be approachable. We need to promote getting out there and meeting our communities far more so that we can achieve some of these items. Above all, we need to be trusted, thus, we need to be honest and ensure our communities know and understand key facts.

\subsection{FEMA's Next Steps}

Following the event, Awareness to Action: A Workshop on Motivating the Public to Prepare, FEMA's (2013) next steps are to:

Revise content and framing for preparedness messaging to include:

- Re-examining preparedness messages;

- Validating science base for protective actions;

- Incorporating insights from disaster survivors; and

- Providing localized risk data.

Tailor implementation by stakeholder and sociodemographic groups to include:

- Launching a new community-based campaign, America's PrepareAthon!;

- Providing tailored preparedness resources and training;

- Supporting workplace preparedness;

- Implementing the National Strategy for Youth Preparedness Education; and

- Encouraging volunteer opportunities.

Engage the whole community by:

- Expanding partnerships at all levels and with all sectors and

- Supporting Citizen Corps Councils.

Refine evaluation and assessment to include:
- Conducting in-depth assessments of whole community preparedness in large urban cities;

- Refining national research activities; and

- Partnering with National Academies of Science to build on the findings in their report, Disaster Resilience: A National Imperative.

\section{A WAY FORWARD}

The recommendations for a way forward in an effort to improve Auckland's preparedness levels will be to develop a set of comprehensive recommendations on which to base our next steps. The recommendations will be based on the findings of FEMA's "Awareness to Action: A Workshop on Motivating the Public to Prepare.". Emerging from these recommendations will be an action plan in which the items identified are systematically addressed.

Moving forward, to enable a higher level of disaster preparedness for Aucklanders, there is a need to translate the notion of social resilience, in particular the "preparedness" message, into practical education programmes which reach all parts of our communities as well as the need to enhance our capacity to provide diverse services to cater for diverse needs.

At this point in time, these conclusions are a reasonable way forward. It is important they are considered as dynamic to match the environment in which they will be delivered.

\section{DISCLAIMER}

The views expressed are those of the author and do not necessarily represent the policies or views of Auckland Council.

\section{REFERENCES}

Aldrich, J., Bennett, B., Carroll, S., Favetti, R., Hansen, J., Morten, D.,...Wong, H. (2008, June 18). The culture of preparedness: Disaster planning and preparedness in San Francisco neighborhoods. Retrieved from http://www.spur.org/ publications/spur-report/2008-06-18/culturepreparedness

Auckland Council. (2014). Community safety action plan 2014-2019 [Draft]. Auckland, NZ: Auckland Council.

Auckland Council. (2013). Civil defence and emergency management Committee: Open agenda [PDF]. Retrieved from http://www. aucklandcouncil.govt.nz/SiteCollectionDocuments/ aboutcouncil/committees/civildefenceemergencym anagementcommittee/meetings/civildefenceemerg encymanagementcomag20130925.pdf

Building Research Institute, \& National Graduate Institute for Policy Studies. (2007). Disaster education.

Cacioppo, J. T., Reis, H. T., Zautra, A. J. (2011). Social resilience: The value of social fitness with an 
88

application to the military. American Psychologist, 66(1), 43-51. http://dx.doi.org/10.1037/a0021419

Committee on Increasing National Resilience to Hazards and Disasters, Committee on Science, Engineering, and Public Policy, Policy and Global Affairs, \& The National Academies. (n.d.). Disaster resilience: A national imperative. Washington, D.C.: National Academies Press.

Dufty, N. (2010). A new approach to community flood education. Paper presented at seventh biennial Victorian Flood Conference, Bendigo, Victoria. Retrieved from http://works.bepress.com/ neil_dufty/4

Dufty, N. (2011). Engagement or education? Australian Journal of Emergency Management 26(3), 35-39.

FEMA. (2011). A whole community approach to emergency management: Principles, themes, and pathways for action. Washington, D.C.: U.S. Department of Homeland Security.

FEMA. (2013) Preparedness in America report. Washington, D.C.: U.S. Department of Homeland Security.

FEMA, \& American Red Cross. (2013). Summary report on awareness to action: A workshop on motivating the public to prepare. Washington, D.C.: U.S. Department of Homeland Security.

Finnis, K. (2004, September). Creating a Resilient New Zealand: Can public education and community development campaigns create prepared communities? An examination of preparedness motivation strategies [PDF]. Wellington, NZ: Ministry of Civil Defence and Emergency Management. Retrieved from http://www.civildefence.govt.nz/memwebsite.nsf/Fil es/finnis_report_final/\$file/finnis_report_final.pdf

Joint Centre for Disaster Research. (2013). Enhancing community resilience through engagement, partnership and empowerment. Research Update, 19, 13

Lake Wobegon. (n.d.). Retrieved Februay 13, 2014 from Wikipedia: http://en.wikipedia.org/wiki/ Lake_Wobegon\#The_Lake_Wobegon_effect

Leitch, L., \& Sutton, L. (2013, June 21). An introduction to the social resilience model. Retrieved from http://www.thresholdglobalworks. com/about/social-resilience/

Manley, C. (2013a). AUT types of CDEM emergency planning.

Manley, C. (2013b). CDEM staff induction 3 September 2013.

McKay, J. (2012, November 12). The preparedness message isn't reaching the public. Retrieved from http://www.emergencymgmt.com/disaster/Prepared ness-Message-Isnt-Reaching-Public.html

Mileti, D. (2003). Public hazards communication and education: The state of the art. Boulder, CO:
Natural Hazards Research and Applications Information Center.

Mileti, D. S. (2008). Changing people's readiness behaviour.

Ministry of Civil Defence and Emergency Management. (n.d.). Key messages for civil defence emergency management. Retrieved from http://www.civildefence.govt.nz/memwebsite.nsf/wp g_URL/For-the-CDEM-Sector-Public-EducationKey-Messages?OpenDocument

Ministry of Civil Defence and Emergency Management. (2010, June). Working from the same page: Consistent messages for CDEM. Retrieved from http://www.civildefence.govt.nz/ memwebsite.nsf/wpg_URL/For-the-CDEM-SectorConsistent-Messages-for-CDEMIndex?OpenDocument

Paton, D. (2006). Disaster resilience: building capacity to co-exist with natural hazards and their consequences. In D. Paton \& D. M. Johnston (Eds.), Disaster resilience: An integrated approach (pp. 3-10). Springfield, IL: Charles C. Thomas Publisher, Ltd.

Paton, D., Smith, L. M., \& Johnston, D. (2005). When good intentions turn bad: Promoting disaster preparedness. Australian Journal of Emergency Management, 20(1), pp. 25-30.

Preston, J. (2012) Disaster education: "Race," equity and pedagogy. Rotterdam, Netherlands: Sense Publishers.

RAND Corporation. (2013). Building resilient communities. Retrieved from http://www.rand.org/ content/dam/rand/pubs/tools/TL100/TL109/RAND_ TL109_training/training.htm

Rhodes, A. (2011). Opinion: Ready or not? Can community education increase householder preparedness for bushfire? Australian Journal of Emergency Management, 26(2), 6-10.

Ripley, A. (2008). The unthinkable who survives when disaster strikes-And why. New York, NY: Crown Publishers.

R. J. Westmore. (n.d.). How to create a culture of preparedness. Retrieved from http://rjwestmore. com/2012/01/1080/

San Francisco Department of Emergency Management. (n.d.). SF72. Retrieved from http://www.sf72.org/home

Slovic, P., Finucane, M. L., Peters, E., \& MacGregor, D. G. (2004). Risk as analysis and risk as feelings: Some thoughts about affect, reason, risk and rationality. Risk Analysis 24(2), 311-322. http://dx.doi.org/10.1111/j.0272-4332.2004.00433.x

Takatori Community Center. (n.d.). Takatori community center, Kobe, Japan. Retrieved from http://www.tcc117.org/en/ 